GONTRIBUTLNS FROM THE HEYE MUSEUM

NUMBR 4

PORTO RICAN ELBOW-STONES IN THE HEYE MUSEUM, WITH DISCUSSION OF SIMII AR OBJECTS ELSEWHERE

BY J. WALTER FEWIES

PROPERTY OF GEORGE G. HEYE 


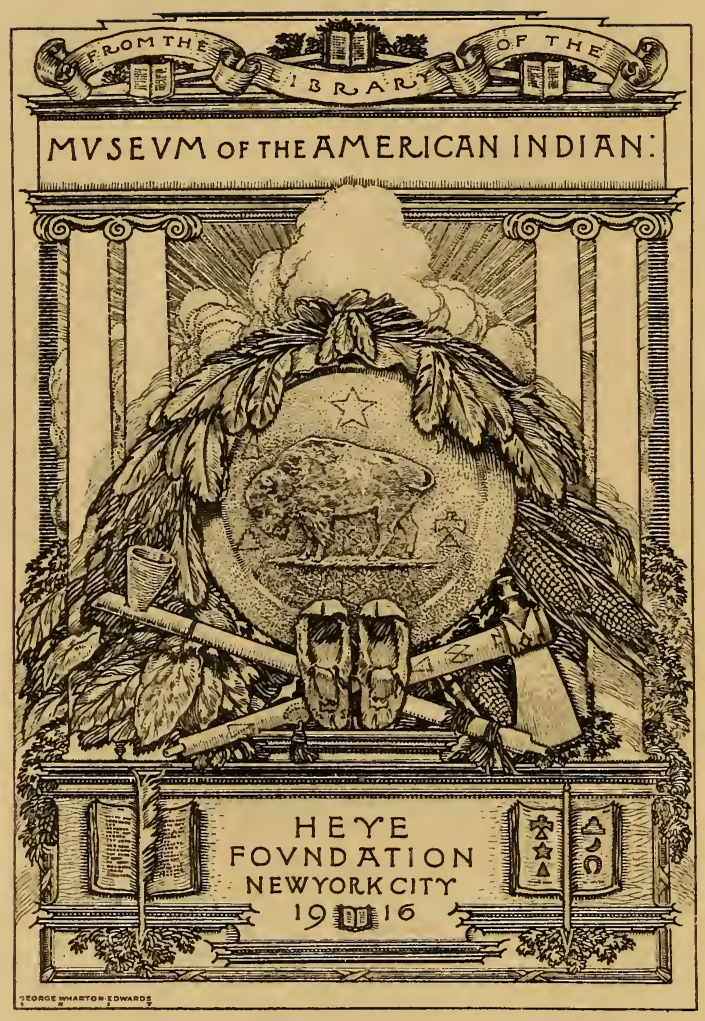



1. Walter Tewhes. 


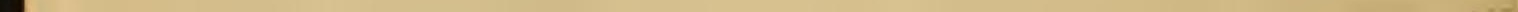


CONTRIBUTIONS FROM THE HEYE MUSEUM

NUMBER 4

\section{PORTO RICAN ELBOW-STONES IN THE HEYE MUSEUM, WITH DISCUSSION OF SIMILAR OBJECTS ELSEWHERE}

By J. WALTER FEWKES

Reprinted from the AmErican ANTHropologist (N.s.), Vol. XV, No. 3, July-September, 1913

Lancaster Pa., U. S. A.

The New Era Printing Company х913

UUL ? 02000

U

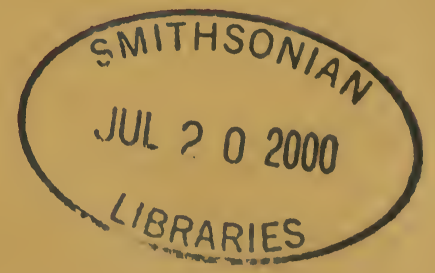



<smiles>C1C[In]C1</smiles> 

[Reprinted from the American Anthropologist, Vol. 15, No. 3, July-Sept., 19I3.]

\section{PORTO RICAN ELBOW-STONES IN THE HEYE MUSEUM, WITH DISCUSSION OF SIMILAR OBJECTS ELSEWHERE}

\section{By J. IVALTER FEIVKES}

\section{INTRODUCTION}

$\mathrm{M}^{\mathrm{A}}$

ANY prehistoric stone objects found in Porto Rico have taxed the ability of archeologists to explain and have furnished the theorist with abundant material for speculation. Among these may be mentioned three-pointed idols, both with and without animal or human heads. Other forms, from their resemblance to horse-collars, have from the first been designated as collars or collar-stones. Those prehistoric Porto Rican stone objects that, from their shape, are called elbow-stones, are the least known and apparently one of the most enigmatical types. The splendid Antillean collection of George G. Heye, Esq., of New York, contains undescribed examples of all these problematical objects, and of these the three elbow-stones here described for the first time are among the most important.

Elbow-stones resemble, in general form, fragments of broken collars, but a detailed study of various elbow-stones and comparison with stone collars, rather than bearing out this seeming resemblance, tends to show that they form types distinguished by highly specialized characters.

The elbow-stone type of objects is represented by twelve specimens in the archeological collections studied by the author. Objects of this type are therefore less numerous than the collars, of which there are about one hundred in different collections. Elbow-stones have not been found in Cuba, Jamaica, or the Lesser Antilles, and have never been reported from the American mainland. Their distribution in the West Indies corresponds closely with that of stone collars and three-pointed stones, which are practically confined 
to Porto Rico, Hispaniola (Haiti and Santo Domingo), and possibly eastern Cuba. The author is of course aware that stone collars and three-pointed stones have been recorded from certain of the Lesser Antilles, but their number, or rather their relative proportion to other prehistoric objects from the same islands, is so small that he is inclined to question the recorded provenance of these specimens. Thus the late Professor O. T. Mason described and figured a single collar in the Guesde collection from Guadeloupe, and M. Alphonse Pinart ascribed another specimen of this type to the same island. Among several hundred stone objects from St Vincent the author has not seen a single collar or three-pointed stone, and he therefore reasonably suspects that the locality of the single broken fragment of the latter type ascribed to St Vincent by $\mathrm{Mr}$ Joyce $^{1}$ is doubtful. It is the writer's belief that these objects are not indigenous to the Lesser Antilles. ${ }^{2}$ With a collar in the British Museum described by Joyce and said to have been found in St Thomas, Danish West Indies, the case is somewhat different. St Thomas, St Croix, and neighboring islands belong to the same prehistoric culture area as Porto Rico, hence stone collars may rightly be expected in them; in fact a fragment of a collar undoubtedly found in St Croix is now in the Nordby collection at Christiansted, the chief city of that island.

As the author intends to point out elsewhere that the localization of characteristic stone objects determines certain archeological areas, he will now only briefly mention the existence of several welldefined prehistoric Antillean culture areas. The majority of stone objects from the St Vincent-Grenada area are radically different from those of St Kitts, and these in turn differ from those of the Barbados area. ${ }^{3}$ Stone collars, elbow-stones, and three-pointed stones are peculiar to the Porto Rico-Haiti culture area, and when found elsewhere in the West Indies are believed to have been introduced.

\footnotetext{
1 Prehistoric Antiquities from the Antilles in the British Museum, Jour. Roy. Anthr. Inst., vol. xxxvir, pp. 402-4I9, 1907.

2 A peculiar form of three-pointed stones from Carriacou, one of the Grenadines, now in the Heye Museum, will be described later.

${ }^{3}$ Trinidad and Tobago belong culturally, as well as geographically and biologically, to the adjacent continent.
} 
Since the three types of Antillean stone objects above mentioned are closely connected, both culturally and geographically, they are logically considered as related, and in order to understand the significance of elbow-stones a more accurate knowledge of the collars is desirable.

The variety of forms and the distribution and character of superficial ornamentation of typical Porto Rican collars have been indicated in the author's work, Aborigines of Porto Rico, ${ }^{1}$ and in the

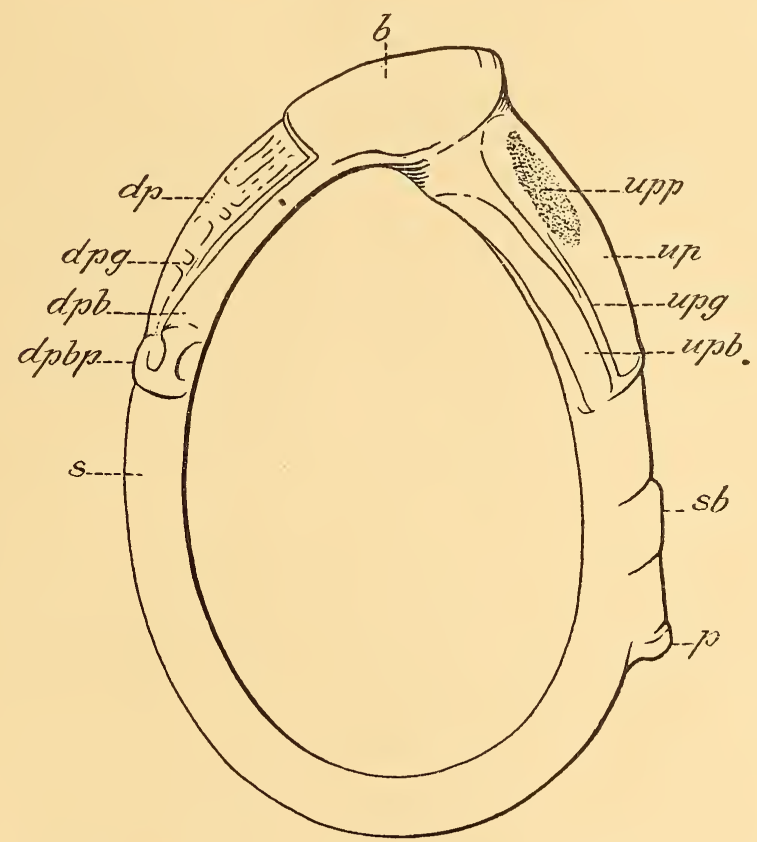

FIG. I I6.-Schematic drawing of a slender, oblique stone collar.

accompanying illustration (fig. I I6) from that report the topography of the surface ornamentation of one of these collars is indicated. Comparison of an elbow-stone (fig. II7) with a broken stone collar shows that the two have the so-called boss $(b)$ and the undecorated panel $(u p)$ in common. On the other hand, the decorated panel $(d p)$, shoulder $(s)$, shoulder band $(s b)$, and projection $(p)$ are not found in elbow-stones. An arm with decoration exists in

\footnotetext{
${ }^{1}$ Twenty-fifth Annual Report, Bureau of American Ethnology, Washington, I907.
} 
the elbow-stone, but when figures are cut in relief on it they are quite unlike those on the decorated panels of collars. The arms of the two types on which the decorations appear are not identical, and the ends of the two arms of the elbow-stones may be fluted or girt with grooves $(g)$, which are not represented in collars.

For convenience of study the two arms of an elbowstone (fig. I I 7 ) may be designated as right and left (RA, LA), and their point of junction the angle or elbow. One of the arms is either decorated or has a panel; the ends of both may be fluted, while their general form tapers more or less uniformly. One or both arms may have a groove on the outside called the sulcus $(s)$, which, when situated on the paneled arm, extends lengthwise from the panel border to the end of the arm. A cross-section of an elbow-stone near the boss following the elbow band ${ }^{1}$ is, as a rule, about the same as that near the pointed pole of an ovate slender collar. The surface of an elbowstone, especially the boss, is gen-

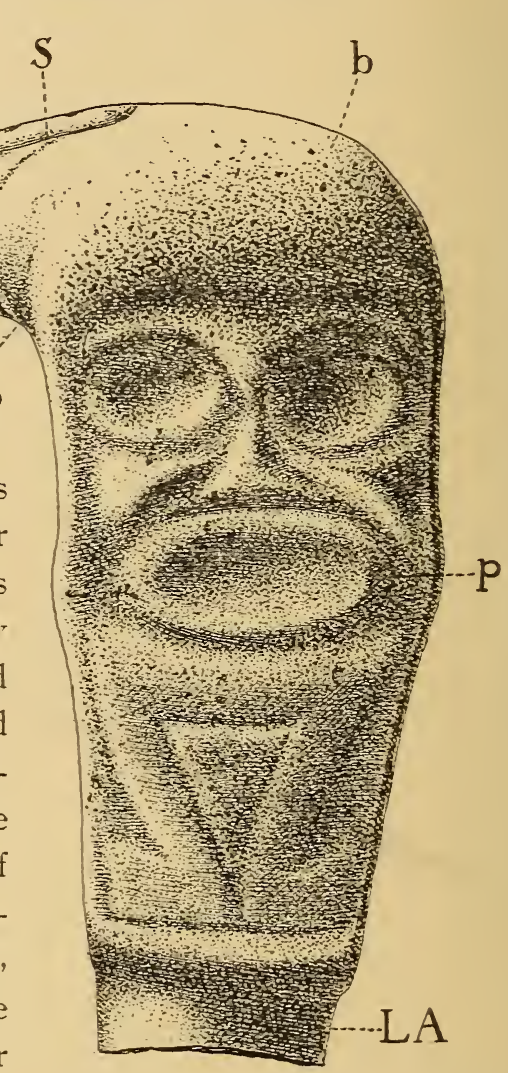

FIG. II 7.-Elbow-stone in the Heye Museum. ( $9 \times 4$ inches.) erally rough, but several examples have the remaining parts finely polished.

So close are the general likenesses between the boss and the arms or shoulders of collars and elbow-stones that an identification

${ }_{1}$ The elbow band $(e b)$ found in some collars and elbow-stones extends transversely across the inner surface from one rim to the other. 
of the latter with broken collars is most natural. In order to explain minor differences in the two types, it is held by some of those who entertain this opinion that a broken collar has been subsequently fashioned into an elbow-stone and its surface redecorated to fit it for secondary use. So radically different, however, are the carvings and symbols on the surfaces of these two types of objects that this conclusion seems unreasonable.

Other archeologists believe that the elbow-stone is a fragment of a type of collar differently ornamented from any that have been found entire. The resemblances are believed by them to be close enough to indicate identity and the differences are looked upon as special rather than as general characters.

The belief that the elbow-stone belongs to a distinct type is far from the thought that there is any utilitarian difference between the two classes of objects. All indications tend to show a like use and that if we could satisfactorily explain the meaning of one type we should be in a fair way to interpret the other. It is, in fact, primarily to shed some light on the significance of the stone collar that the author presents the following results of his comparative studies.

Elbow-stones, like stone collars, may be divided into righthanded and left-handed, or right-armed and left-armed, according to the position of the decorated arm. When an elbow-stone is placed so that the panel will show, ${ }^{1}$ this feature will be seen either on the right or the left hand, thus determining the designations "right-handed" and "left-handed" elbow-stones. The significance of the difference in this feature is not known-it may mean nothing, but it would appear that its very occurrence in both collars and elbow-stones has some important bearing on the function of the objects.

The style of ornamentation furnishes data for a classification of elbow-stones on other grounds. Two distinct varieties of these objects can be readily recognized accordingly as a head, face, or

1 Professor Mason determined this feature by the position of the "projection," which does not exist in elbow-stones. He figured stone collars with their shoulders above and the pointed ends below. The position adopted by the present author as natural for both elbow-stones and stone collars has the pointed pole above. 
body is sculptured on the outer surface of one of the arms. This sculpture, when it appears, is generally in low relief, and always

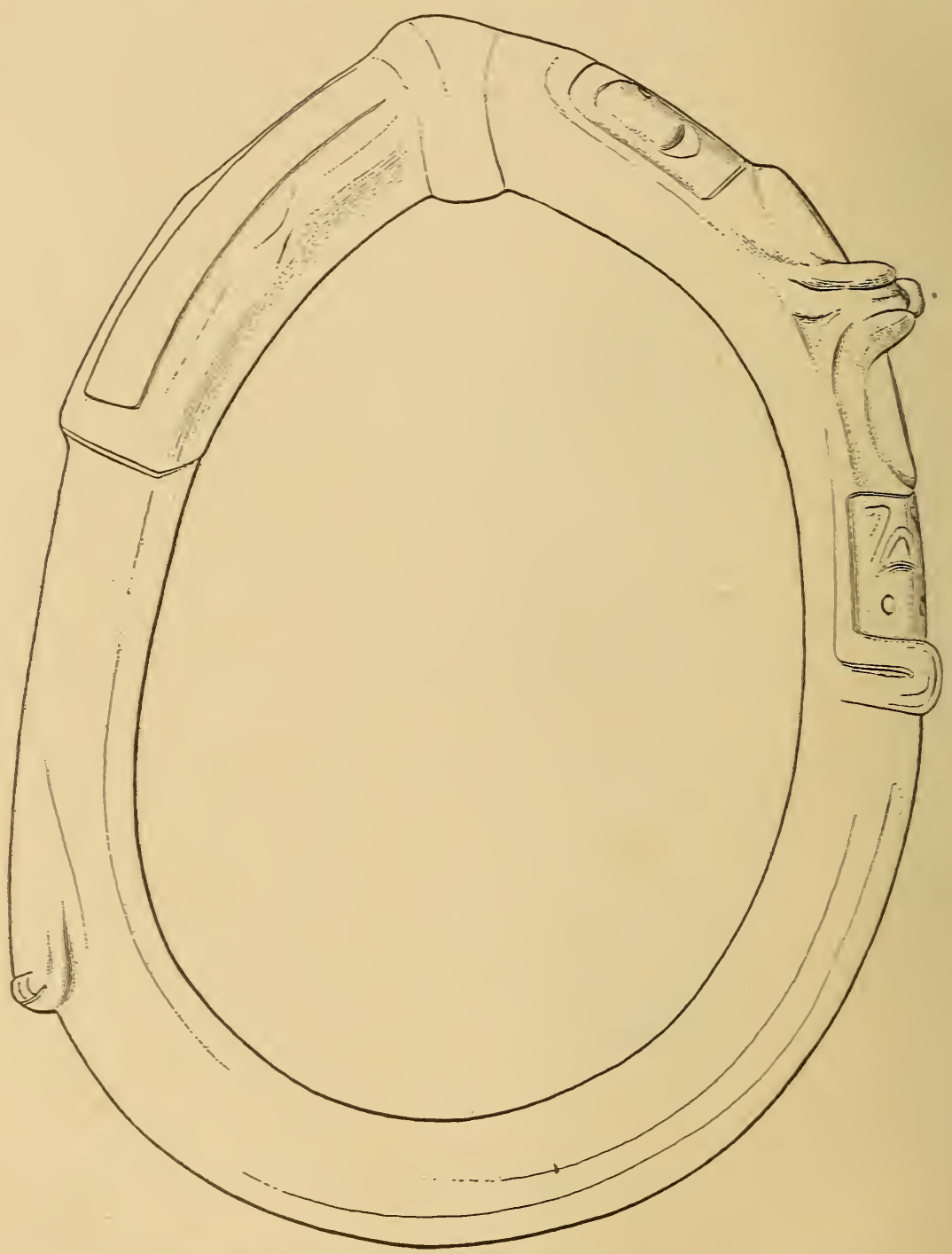

FIG. II8.-Massive stone collar in the Heyre Museum. (201/2X I5 inches.)

represents human features, nerer those of an animal. In elbowstones on which such a sculptured figure does not appear, there is 
always a panel with a shallow, oval, concave pit hollowed in the middle, in which is sometimes a secondary depression, as shown in figure 125 . The arm bearing this panel with its pit corresponds with that on which, in decorated elbowstones, is cut a human head or body. A homologue of this plain panel (identical with the undecorated pariel of a stone collar) does not occur on those elbow-stones in which carved heads or faces are found, consequently it is supposed that the decorated panel of the stone collar is not represented by a sculptured head in elbowstones. ${ }^{1}$

${ }^{1}$ If the arm of an elbow-stone that bears a panel is the same as that with the decorated head, it is not improbable that a head was formerly attached to the panel. Acosta has suggested that a three-pointed stone was attached to the undecorated panel of a stone collar, in which case the resemblance to an elbow-stone with head on the arm would be striking. It is instructive to note that as a rule those elbow-stones that have a figure cut on one arm have, when the arm is unbroken, a sulcus and grooves on the same arm, while those with a panel have the sulcus and grooves on the opposite arms. Few of the specimens have sulci on both arms, a lack which opposes the theory that there was ever a wooden connection, but the best specimens have,the end of both arms fluted.

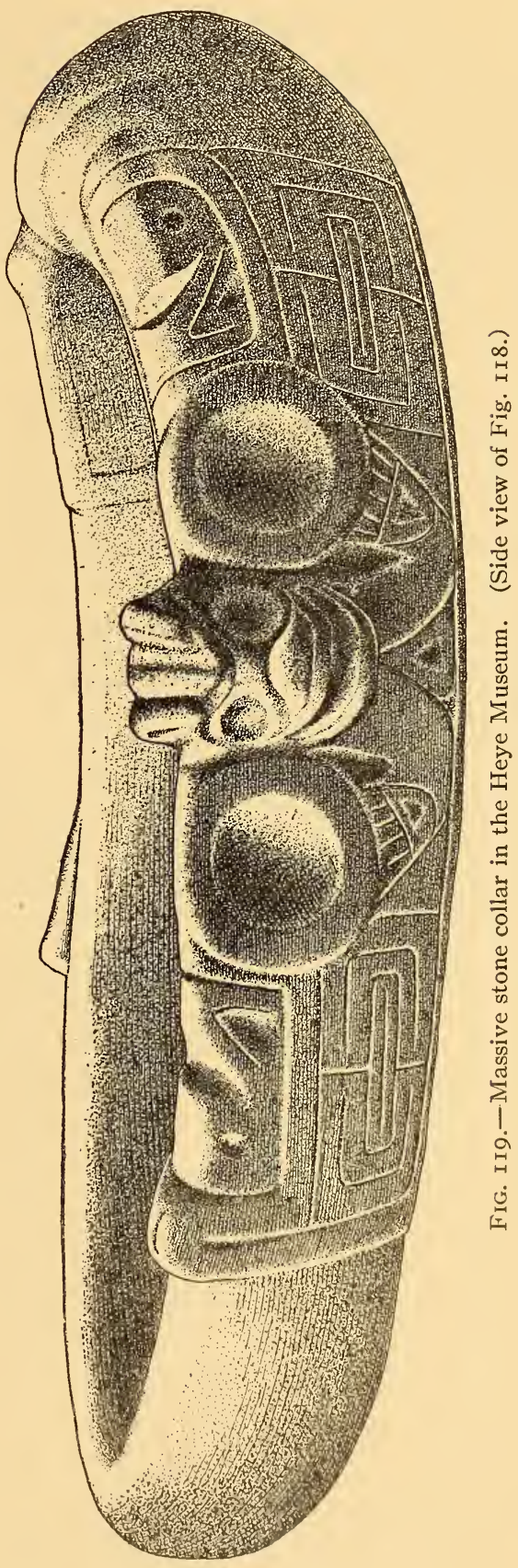


In those specimens of elbow-stones in which a face is sculptured on one arm, it will be noticed that the middle line of the face or head is placed longitudinally and not transversely to the axisalways lengthwise of the arm, never crossing it. The position of these figures on known elbow-stones differs radically from that of the heads on panels of stone collars, for in the latter the middle line of the face is at right angles to the panel. The figure on a collar is situated generally on the border of the decorated panel, and is small and in low relief; but in an undescribed collar in the Heye Museum (figs. II8, II9), which is unique in this respect, the head rises above the surface. An examination of this collar shows that in general form it belongs to the massive stone-collar group, while the decoration is more like that of the slender oval collar; but the head cut on the panel is so different from any yet described that it can hardly be assigned to the latter group. It is therefore regarded as a connecting form having affinities with both massive and slender oval collar stones.

It is instructive and may be significant that the faces on all the elbow-stones are anthropoid, and the same is true also of the stone collars, the heads on all of which have human features. The symbolism of the spirit depicted represents a human, not an animal, zemi.

\section{Description of Elbow-stones}

The following classification includes the known elbow-stones in various collections, designated by the name of the owner, the collector, or the museum in which they are deposited.

\section{A. With face cut in relief on one arm}

$a$. Face on the right arm

I. Madrid specimen (fig. I20)

2. Heye Museum specimen (figs. I21, I22)

3. Latimer specimen, National Museum (fig. 123)

b. Face on the left arm

I. American Museum specimen

2. American Museum specimen

3. Pinart specimen

4. Heye Museum specimen (fig. I I 7 ) 
B. Arm without face, but with" panel

a. Panel on the right arm

I. American Museum specimen

2. American Museum specimen

3. American Museum specimen

4. National Museum specimen (fig. I24)

b. Panel on the left arm

I. Heye Museum specimen (fig. I25)

C. Elbow-stone of doubtful type

A. WITH FACE CUT IN RELIEF ON ONE ARM

a. FACE on the Right ARM

I. Madrid specimen.-The most perfect and elaborately decorated of all these objects is an elbow-stone in the Museo Arqueo-

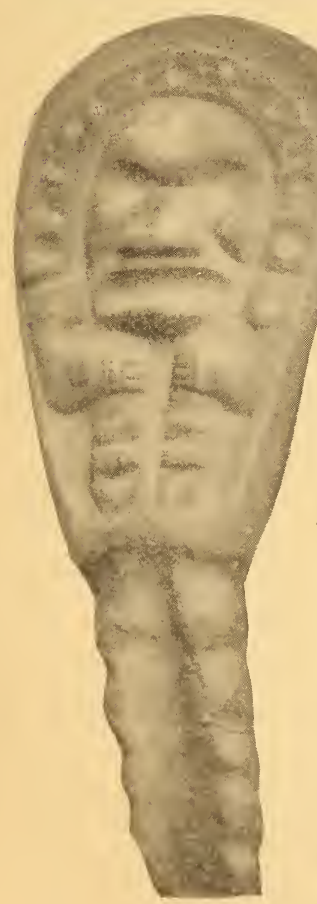

logico of Madrid, which has face, arms, and legs sculptured on one arm. This specimen has been figured by Neumann and several other writers, but as it is almost unknown to archeologists a new illustration (fig. I2O), indicating the variations in the decoration of these objects, is here introduced. ${ }^{1}$

From an inspection of the figure it appears that both arms of this beautiful specimen, unlike those of most elbow-stones, are unbroken. The right arm shows the longitudinal groove (sulcus) common to these objects, extending from the lower margin of the panel to the extremity of the arm. The surface is almost wholly occupied by the figure sculptured upon it, the head, arms, legs, and horseshoe-shaped headFIG. I20. - Elbow- band or fillet being in relief. This fillet, which stone, Madrid specimen. (12 $\frac{5}{8}$ inches.)

1 The accompanying figure was made from a photograph obtained in Madrid in I9I 2 by Professor M. H. Saville. It is a pleasure to acknowledge my indebtedness to him and to my friend sr Nacisso Sentenach who made the photograph from which the illustration is reproduced. 
is of about the same breadth throughout, is decorated with a number of incised pits, one of which is placed medially over the forehead. The fillet ends on each side of the face, near the cheeks, where there are depressions apparently representing ears. This headband recalls those found on heads of three-pointed stones, with which it is seemingly homologous. The two ends of the fillet merge into the shoulders of the figure and continue to form

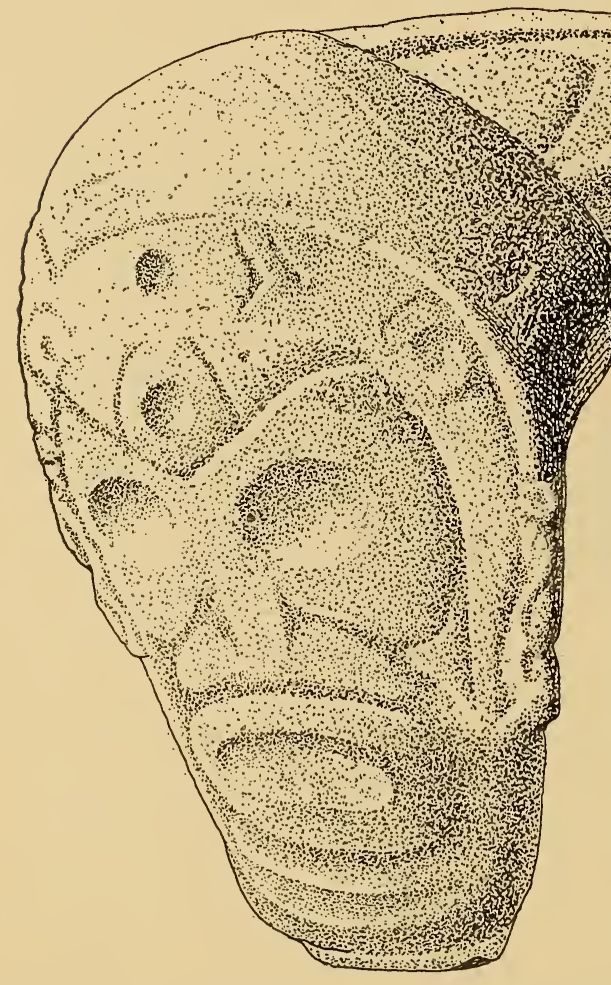

FIG. I2I.-Elbow-stone in the Heye Museum. the arms. The forearms are folded on the breast, as is common in Antillean objects of art in stone and shell, and the fingers are rudely represented by grooves. Near the wrists, a short distance from the fingers, there is a slight projection on each arm which recalls the protuberances commonly represented on the ankles of Antillean figures. Relatively the body is abnormally small or inadequately represented, the space between chin and legs being so restricted that not even the umbilicus, so constantly found in stone images from Porto Rico, is represented. The soles of the feet are turned upward in an extraordinary way, and the toes are folded back, a common feature in Antillean idols. The mouth is large, nose broad, cheeks prominent, the whole recalling faces on three-pointed stones. 
2. Heye Museum specimen.-The second specimen of elbow-stone (figs. I2I, I22) with a face on the right arm is less elaborately sculptured than the Madrid example, the arms and body not being represented. The right limb is apparently broken off just below the carved face, so that there is nothing on this arm corresponding to a feruled end. On the forehead of the figure may be seen a triangular area in which is a central pit. The head is fringed by a fillet less elaborately made than that of the Madrid specimen. The end of the small arm appears to have been broken, there being no sign of fluting, although it shows indications of a sulcus. On the outer side of the small arm, near the angle, there are two series of parallel lines, or chevrons, cut in the surface, recalling the decoration of a massive collar elsewhere figured. ${ }^{1}$

In order to compare this elbowstone with certain stone heads figured by the author in his Aborigines of Porto Rico (pls. LI, LII, LIII) we may suppose that the two arms are much reduced in length, as in plate LII here referred to, and the face cut in high relief instead of being low or flat. A still further reduction in the homologues of the arms appears in certain stone heads

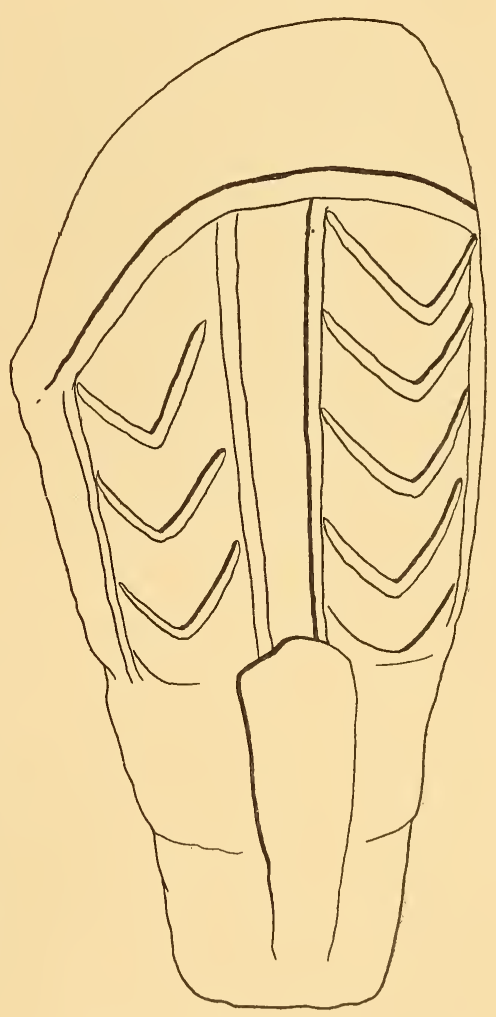

FIG. I22.-Elbow-stone. Sketch of

Fig. I 2 from the top. and in stone disks with faces illustrated in the plates mentioned, in some instances all traces of the arms having disappeared. The stone head shown in plate LIV $a a^{\prime}$ has the neck developed into a short handle, giving the appearance of a baton and recalling certain ceremonial celts. ${ }^{2}$ The objects called "stone heads" in

${ }^{1}$ Aborigines of Porto Rico, op. cit., pl. Lxiv.

2 See Joyce, op. cit., and Twenty-fifth Report Bureau of American Ethnology, pl. xv. 
the author's work above cited so closely resemble three-pointed stones that they may be allied to the third type of zemis, in which the conoid projection is modified into a head. A like parallel occurs in the first type of three-pointed stones, the heads of which recall those of men, lizards, and birds. The few known specimens of the second type have human faces.

The figures representing lizards in both the first and the third type of three-pointed stones are characterized by elongated snouts, eyes, and two pits, representing nostrils, placed near the extremity of the upper lip. The human faces of the first type generally have the ornamented fillet reaching from ear to ear, which is never represented in reptilian three-pointed stones of the first type, but is present in reptile figures in the third type. Ears appear in human but never in bird or reptilian forms. In place of a depression or pit in the median line of the head-band, the reptilian figures of the third type have a device consisting of a low convex projection and pit of the first form. This last-mentioned feature is sometimes situated in a fold extending downward over the forehead, suggesting a frontal ornament.

3. Latimer specimen.-This elbow-stone (fig. I23) was first figured by Professor O. T. Mason, ${ }^{1}$ who regarded it as a part of a collar, ${ }^{2}$ and afterward by the author, who founded the type now known as elbow-stones upon its characteristics. Although the form of the Latimer elbow-stone is somewhat aberrant in several particulars, it presents the distinctive features of the type. Its arms are apparently unbroken at their extremities, and the face is cut on the right limb. Instead of the encircling grooves on the arm bearing the face, the arm is perforated near its end, where it is crossed by a single transverse groove supposed to serve the same purpose as the grooves in the fluted specimens above considered; in other words, for attachment to a staff or some other object. The oval face; eyes, nose, and mouth are typical of Antillean art. The head-band has a pit medially placed above the forehead and is

1 The Latimer Collection of Antiquities from Porto Rico in the National Museum at Washington, D. C., Smithsonian Report for $I 876$.

2 The Aborigines of Porto Rico and Neighboring Islands, Twenty-fifth Annual Report, Bureau of American Ethnology, I907, pl LxIX. 
ornamented by a series of parallel incised lines. The slightly protruding ears at the termini of the head-band have large circular pits. The shorter arm has a shallow longitudinal groove (sulcus?) and obscure elbow-band.
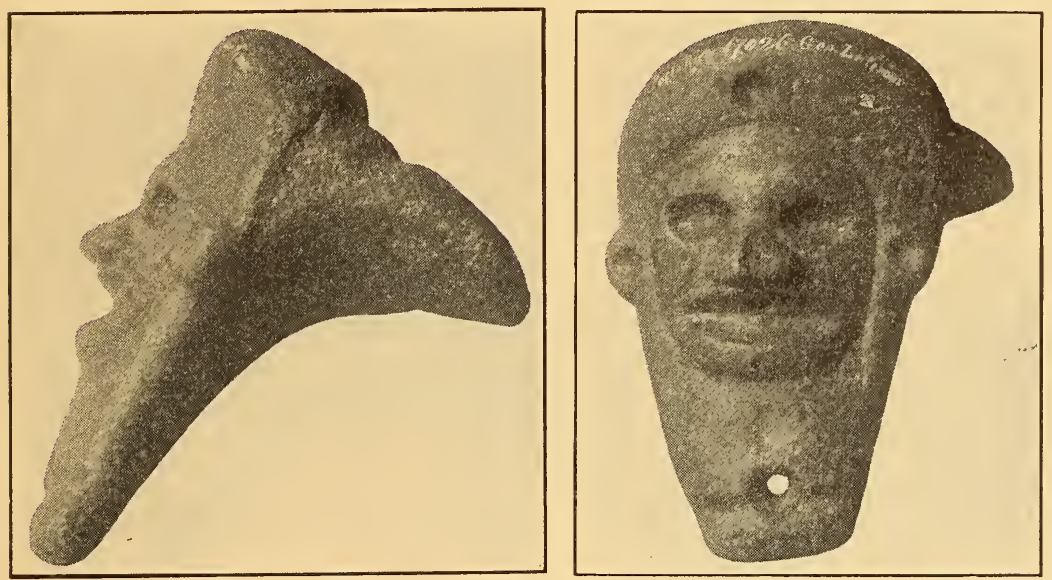

FIG. I23.-Elbow-stone in the Latimer collection. Side and front views. (Length $71 \frac{1}{4}$ inches.)

b. FACE on the Left Aru

I. American Museum specimen.-Among the elbow-stones in the American Museum of Natural History there is an instructive specimen in which an arm is ornamented with a human face in relief, portions of the body, and anterior appendages; the legs are drawn together and merge into a beaded end with longitudinal sulcus and accompanying encircling grooves. The face sculptured on this specimen is oval; the cheeks are prominent, the eyes and mouth circular. The ear pits are prominent and the fillet or headband bears a medial circular protuberance with its accompanying pit. The arms are bent; the legs are separated above by a space in which is a triangular depression. The umbilicus is indicated by a circular design. The shorter arm is girt by parallel grooves and tapers to a rounded extremity.

2. American Museum specimen.-In the same Museum there is a second specimen of elbow-stone, on the left arm of which is carved 
a rude face. This example is broken on one edge. It has no grooved arms, but in place of them is a perforation near the end of one arm, as in the Latimer specimen. The sulcus is absent.

3. Pinart specimen.-The Pinart elbow-stone, said to have been at one time in the Trocadero Museum, Paris, belongs to that group in which the left arm is the larger and bears an oval face which has large open mouth, prominent ears and head-band, with a circular pit over the forehead. Representations of arms, legs, and

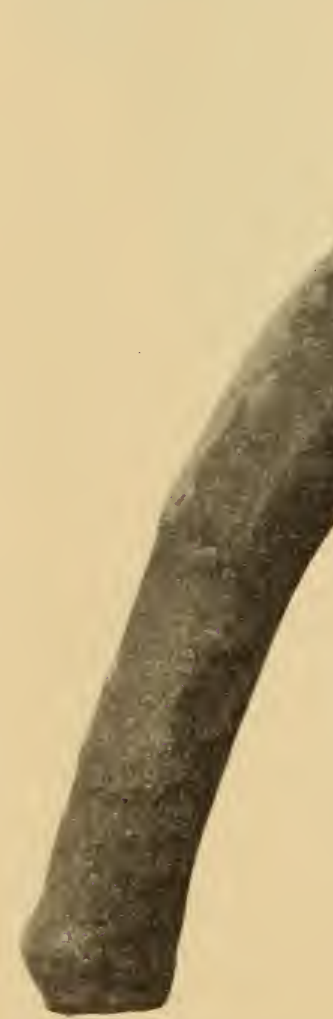

FIG. I24.-Elbow-stone in the United States National Museum.

umbilicus are present: the legs are separated by a triangular depression as in a former specimen. In the figure given by Pinart ${ }^{1}$ there are indications of the grooves or furrows of the terminal ends of both arms, but as his illustration is imperfect this feature is difficult to determine satisfactorily.

B. ARM WITHOUT FACE, BUT WITH PANEL

a. PANel ox the Right Arir

There are five ${ }^{2}$ specimens of elbow-stones with flat panels instead of figures on the arms. Three of these are in the American Museum of Natural History, $\mathrm{New}_{4}$ York, a single specimen of the same type

1 Note sur les pétroglyphs et antiquités des Grandes et Pelites Antilles, pl. Io, I89o.

${ }^{2}$ Two of these are figured by J. B. Holder in an article, "The Stone Period of the Antilles," Scribner's Monthly, August, I875. 
is in the National Museum collection, and there is one in the Heye Museum. All, except the last, are right-handed.

These objects are simpler in form than those of the previous group, otherwise they are of the same general character. Each has a sulcus on the surface of one arm, which, however, is without encircling arm grooves. Although the panel pit, a constant feature of the panel, is about uniform in position, it varies in shape and size in the several specimens. From its general shape and simplicity it would appear that the panel in these specimens served as a base to which another object, possibly a stone head, was attached.

The specimen in the National Museum (fig. I24) is said to have been collected at Vieques island, the only locality excepting Porto Rico from which elbow-stones have been recorded. ${ }^{1}$ The paneled arm of this specimen is long and slender, the other limb short and grooved, but with a well-marked sulcus not shown in the figure.

b. Panel on the Left Arm

I. Heye Museum specimen.-The left-hand elbowstone (fig. I25) in the Heye Museum is a fine specimen, surpassing the others of the same group in form and superficial polish. Its left arm ends in a series of bow-stone in the fluted joints, but is without a sulcus; the right arm is

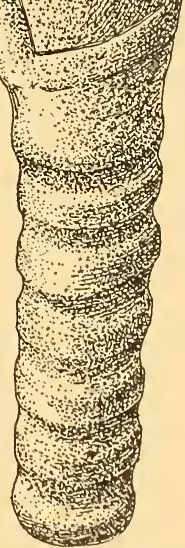

FIG. I25.-E1Heye Museum. short, with an encircling groove. The panel is almost wholly occu-

1 The Madrid specimen may have come from Santo Domingo. Although Vieques Island had been conquered by the Caribs, like Santa Cruz and St Thomas it belongs to the Porto Rico culture area. The Greater Antilles practically end at Anegada channel, geologically, biologically, and culturally. It will be shown in a later publication that all the islands from this channel to Trinidad had a culture, divided into minor groups, which was largely agricultural (Tainan). This culture, especially in the volcanic islands, had been overlaid by Carib elements. 
pied by an elongate oval depression in which is a second oval pit, the surfaces of both of which are smooth. The panel is surrounded by a polished border, slightly raised and evenly rounded.

\section{ELBOW-STONE OF DOUBTFUL TYPE}

There are one or two aberrant specimens that are doubtfully identified as elbow-stones. In discussing the Guesde collection Professor Mason figured ${ }^{1}$ and described an unusual object from
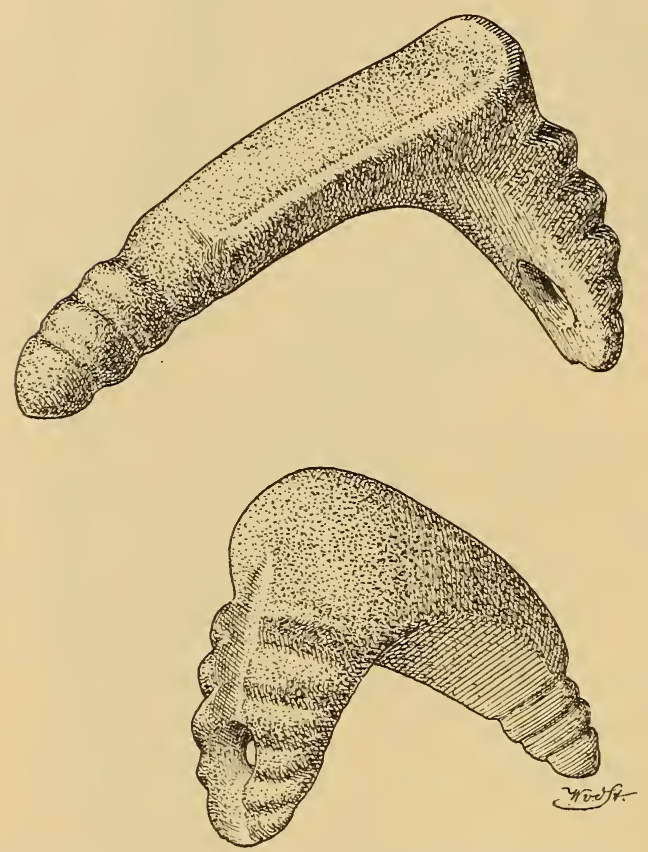

FIG. I26.-Two views of an aberrant elbow-stone in the Guesde collection of the Museum für Völkerkunde, from a drawing made in I9I3. (One-third size.)

"similar specimen" in the American Museum, referred to by Mason, is possibly one of those above mentioned under group B.

The Guesde stone is exceptional in several particulars. The figure shows no indication of a panel or a head, and the sulcus like-

1 Guesde Collection of Antiquities in Pointe-à-Pitre, Guadeloupe, IVest Indies, Smithsonian Report for 1884 , reprint 1899 . 
wise is missing. On account of the absence of the panel it is difficult to tell whether it belongs to the right-arm or the left-arm group. The fluting on the longer arm reminds one of the specimen in the National Museum at Washington (fig. I24), and the perforated shorter arm is like that of the Latimer specimen (fig. I23). The grooves of the smaller arm extend halfway round the arm, while those of the longer arm girt it entirely.

\section{MORPHOLOGY AND INTERPRETATION}

The many similarities between three-pointed zemis, elbowstones, and stone collars would seem to indicate a corresponding similarity in use, consequently any light on the morphology of one would aid in the interpretation of the other types. ${ }^{1}$ The author believes that the life figures on these three types of objects are symbolic representations of zemis, or spirits, which were worshiped by the prehistoric Porto Ricans. They were idols, and bore the name of the particular spirit represented (as well as the general designation "zemi"), a usage common to primitive religions.

A consideration of the differences in form, or the morphology, of these objects is desirable before the many theories as to their use can be intelligently discussed.

A forward step in the interpretation of the morphology of stone collars was taken by $\mathrm{Mr}$ Josiah Cato ${ }^{2}$ and later by Professor Mason who recognized that the "shoulder ridge" faintly resembles a lashing of the two ends of a hoop. ${ }^{3}$

An important suggestion has been made by $\mathrm{Mr}$ T. A. Joyce ${ }^{4}$

1 A discussion of the many theories suggested to explain the meaning and use of stone collars would enlarge this article to undue proportions, hence the question will be considered elsewhere. In the following pages one of these uses is incidentally considered.

2 Dr Holder (The Stone Period of the Antilles, Scribner's Monthly, August, 1875) quotes Mr J. Cato (I869) as follows: "The other [region of collar] on the side of the ellipse, may, perhaps, be intended to represent the ends of a hoop which have been laid together and bound by a ligature."

3 The most serious objection to the majority of theories of the use of Porto Rican stone collars is that they fail to explain a constant feature, the "shoulder band and projection." These features appear in most collars of both the massive and the slender oval varieties.

${ }^{4}$ Prehistoric Antiquities from the Antilles, in the British Museum, Jour. Royal Anthr. Institute, vol. xxxvir, pp. 402-4I9, pl. XLVIII-LVI, I907. 
that the Antillean stone collar is a copy of an archaic zemi made of branches of a tree bent into a hoop and fastened at their ends. He was the first to associate the stone collar with "tree worship," an important advance in the solution of the enigma. Mr Joyce described a stone collar in the British Museum in which there is no shoulder ridge but what appear to be the two ends of branches "overlapped" and "hooked together" at the point where the shoulder ridge ordinarily is found. This led him to suggest that in studying a stone collar we must "retranslate" it to its wooden prototype and recognize that the juncture of the ends in this case (and perhaps in all) was effected as follows: "When the limbs of the fork [of a tree] were trimmed, the stump of a small subsidiary branch, growing in a convenient position towards the end of each, was left projecting; the longer limb was bent round, and the projection towards its termination was hooked round the projection on the shorter limb; the addition of a cotton bandage would hide the joint and make all secure." (P. 4Io.)

"It is perfectly obvious," Mr Joyce says, "that these collars were constructed originally of wood; a young tree was selected and cut off immediately below a fork; the two ends of the fork were trimmed into unequal lengths, the longer bent round so as to overlap the shorter, and the two fastened together by a band of cotton similar to the leg-bandages worn by the natives." He also states (p. 4Io): "Starting with the supposition that they were originally constructed of wood (which seems to me to be almost certain), it seems possible that a clue might be found in the prevalence of tree-worship in the Antilles." 1

"The heavy collars," continues Mr Joyce, "which appear to have been formed of a single and comparatively stout stem bent into a hoop and the ends secured by a bandage, may represent zemi made originally from the straight trunk of a tree without a fork." Thus a second and important step in the interpretation of the meaning of the collar was taken by Joyce in the recognition of the collar as a zemi connected with tree worship, its original prototype

${ }^{1}$ In a future publication an effort will be made by the present writer to identify the spirit of the tree or bush represented by the images on elbow-stones, three-pointed stones, and stone collars. 
being made of wood, the stone form being a more lasting one, but one in which certain characters of the wooden or archaic form still persisted.

In Ramon Pane's account of how Antillean wooden zemis were made, as directed by a tree spirit, we have evidence of tree worship in Haiti, but the testimony afforded by this account is too meager to prove that when the tree referred to by the Catalan father was felled it was made into the form of a collar. The author suspects that the idol referred to by Ramon Pane represented the Yuca Spirit, but this suspicion is still subject to proof.

In Antillean as in other tree worship it was the spirit of the tree that was the object of adoration, and that worship was more or less connected with the material benefits desired: generally the food that the tree yielded. The deity that controlled the manioc (yuca), or the Yuca Spirit, Yucayu, was worshiped for temporal benefits, the wooden idol being the visible, material symbol. ${ }^{1}$

In differentiating the elbow-stone from the collar as a distinct type, it has been shown above that the position of the heads of both relative to the axis does not coincide, since one is transverse to the axis, the other longitudinal. In one case the object must be placed vertically, in the other horizontally, in order to bring the face into a normal position-a difference in position that remains to be satisfactorily explained. If, however, the elbow-stone was carried, it may be that one arm only of the elbow-stone was attached to a staff and the object carried upright, while the collar was laid horizontally when in use, bringing the head ${ }^{2}$ into the same relative position.

It is evident that the furrow, or sulcus $(s)$, is an important feature in the morphology of elbow-stones. This groove, nonexistent in the collars, may have been cut in the surface of the elbow-

1 Attention is called to the fact that as yet no collar, elbow, or three-pointed idol made of wood has been found, although several wooden ceremonial objects have been recorded from caves in Haiti, Jamaica, and the Bahamas. The discovery of a wooden collar would serve as a most valuable and decisive support of Mr Joyce's suggestion.

2 The two known collars besides that shown in figures I 8 and I I 9 with heads cut on the decorated panel border have these faces in the same relative position as that shown in the figures cited, while in all elbow-stones they are at right angles and resemble figure I 7 in this particular. 
stone for the insertion of a rod or staff to which it may have been lashed with cords held in place by the grooves girdling the arm. It is not always limited to one arm, but is sometimes found on both arms, and it would appear that occasionally either two sticks were attached to the stone, one at each end, or the two ends of the same stick were bound to the arms, in which latter case the stick would have to be bent into a hoop resembling in shape a stone collar, part wood, part stone, the elbow being of the latter material.

The attachment of an elbow-stone to a rod or staff was probably by means of regetal fibers; in some instances this was unnecessary, since there was sometimes a depression in the end of each arm, as in an elbow-stone reputed to be owned by $\mathrm{Sr}$ Balbas of Porto Rico, to which reference has been made elsewhere, but which the author has not examined. In this case it appears as if there are depressions in which the sticks were possibly inserted, rather than lashed to the stone.

The theory that the extremity of a staff was laid in the sulcus and lashed to the elbow-stone would preserve the normal position of the face carved on the panel if held vertically. If carried by means of this staff, the face cut on the arm would be upright or in a natural position. Some of the elbow-stones (fig. I 27 ) may hare been carried in the hand without an attached staff, thus accounting for the absence of a sulcus.

The close resemblance of the faces on the elbow-stones to those on three-pointed zemis has already been mentioned. There are other likenesses between these objects, for it sometimes happens that the anterior and posterior ends of three-pointed stones are so elongated that their length equals the arms of an elbow-stone. (See fig. I27.) These resemblances may signify that the three-pointed stone is morphologically related to the elbow-stone.

Three-pointed stones, as other writers hare shown, generally, but not always, bear surface eridences of worn grooves indicating a former attachment by cords or bands. Especially are these evident in three-pointed stones belonging to the first and second types, where a ridge is often found back of a groove at the base of the conoid apex. The wear of the lashing by which it was tied 
can sometimes be observed in this groove, where the stone is quite smooth. The general likeness of the three-pointed stones and the elbow-stones leads one to compare the so-called anterior or head end of the former to the arm of the latter on which the head is cut, while the posterior end would represent the other arm of the elbowstone. In this comparison the conical region of the three-pointed stone would be homologous to the elbow. Following out this comparison we can suppose the three-pointed stone was attached to a staff in much the same way that the elbow-stone is theoretically supposed to have been lashed, as above set forth. ${ }^{1}$

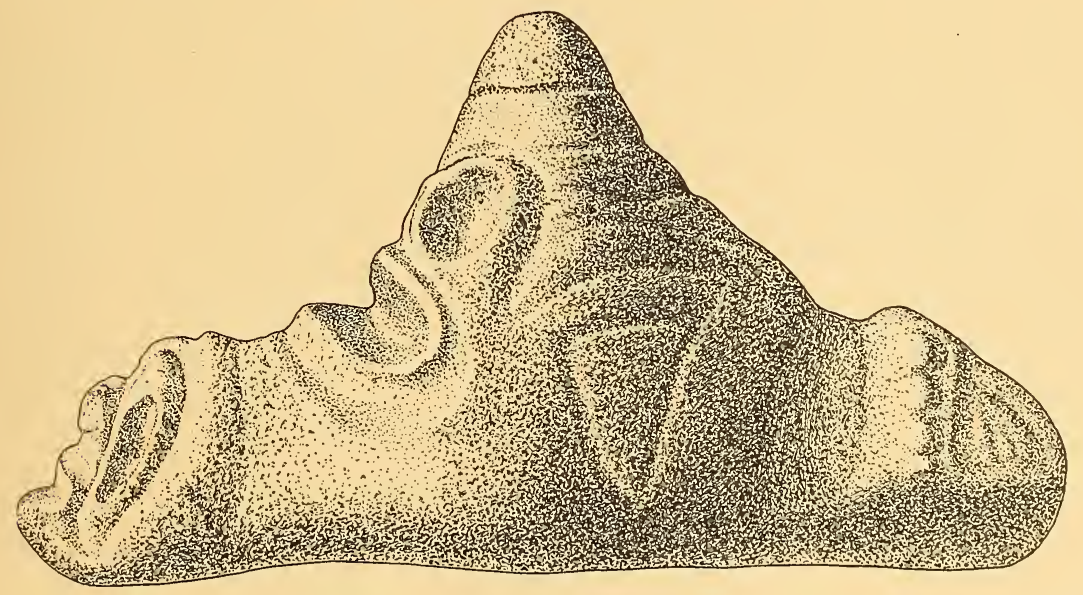

FIG. I2 7.-Aberrant form of elbow-stone in the Heye Museum. (Length 8 inches.)

The classification of three-pointed stones indicated in the author's Aborigines of Porto Rico, where like forms of these objects are grouped into types, is more or less arbitrary, but it is believed to be a convenient one for scientific comparison. Additional specimens of three-pointed stones, unknown when the classification was suggested, have since come to light, and it is found that a few of these forms are aberrant and do not fall naturally into any one of the four divisions suggested. One of these (fig. 127), in the Heye

'Among Guiana Indians, according to im Thurn, "the Ackawoi have one dance in which each of the performers represents a different animal; and in this each carries a stick on which is a figure of that animal" (Among the Indians of Guiana, p. 324, I883). The prototype of the stone zemi among the Antilles was like that of wood aniong the Orinoco tribes. 
Museum, has the three-pointed form, but with the distinctive sculptural features of both the first and second types; that is, this specimen has a head cut on the anterior end and another head or face on the side of the conoid projection just above it, and therefore has distinctive features of both the first and the second type. The specimen referred to is exceptional in other features. While its general form, as seen from one side in the accompanying figure, shows profiles of the two faces and also the superficial sculpturing on one side of the conoid projection, the posterior end, as in the first type of three-pointed stone, has representations of retracted legs, ${ }^{1}$ a feature foreign to most known and all described specimens of three-pointed stones of the second type. The lateral and real surfaces of the conoid projection are ornamented with an incised groove which, strangely enough, extends to the region of the ears, where it ends in a triangular figure forming an appendage quite unlike the ear of any known Antillean idol. There are several other three-pointed stones in which the conoid process is ornamented with incised lines, and one other in which the lines are rectilinear; but they are generally curved lines-spirals, circles, and the like. Straight lines with sharp angles are rarely found on three-pointed stones.

\section{Ceremonial Batons of Stone}

An examination of certain celts, clubs, and other stone artifacts leads to the belief that the prehistoric Antilleans had many kinds of objects which they carried in their hands on ceremonial or other occasions. Several of the almond-shaped or petaloid celts with heads or human figures cut on the sides have their pointed ends prolonged into a handle; ${ }^{2}$ and even those without such a prolongation can hardly be supposed to have been hafted, as in such a case much of the design cut upon them would have been concealed. Many of the beautiful axes for which the island of St Vincent is famous were too bulky to be carried in war and too dull to be used

1 The author has lately acquired, through the courtesy of Professor Saville, a photograph of a three-pointed zemi with a head on the posterior as well as on the anterior end, a condition unique in the many known specimens of the first type.

2 See Joyce, op. cit. 
as cutting implements. They may have been carried by chiefs on ceremonial occasions as badges or insignia of office. ${ }^{1}$

A remarkable stone object (fig. 128) in the Heye collection has the appearance of having been used as a baton, but its form ${ }^{2}$ is differ-
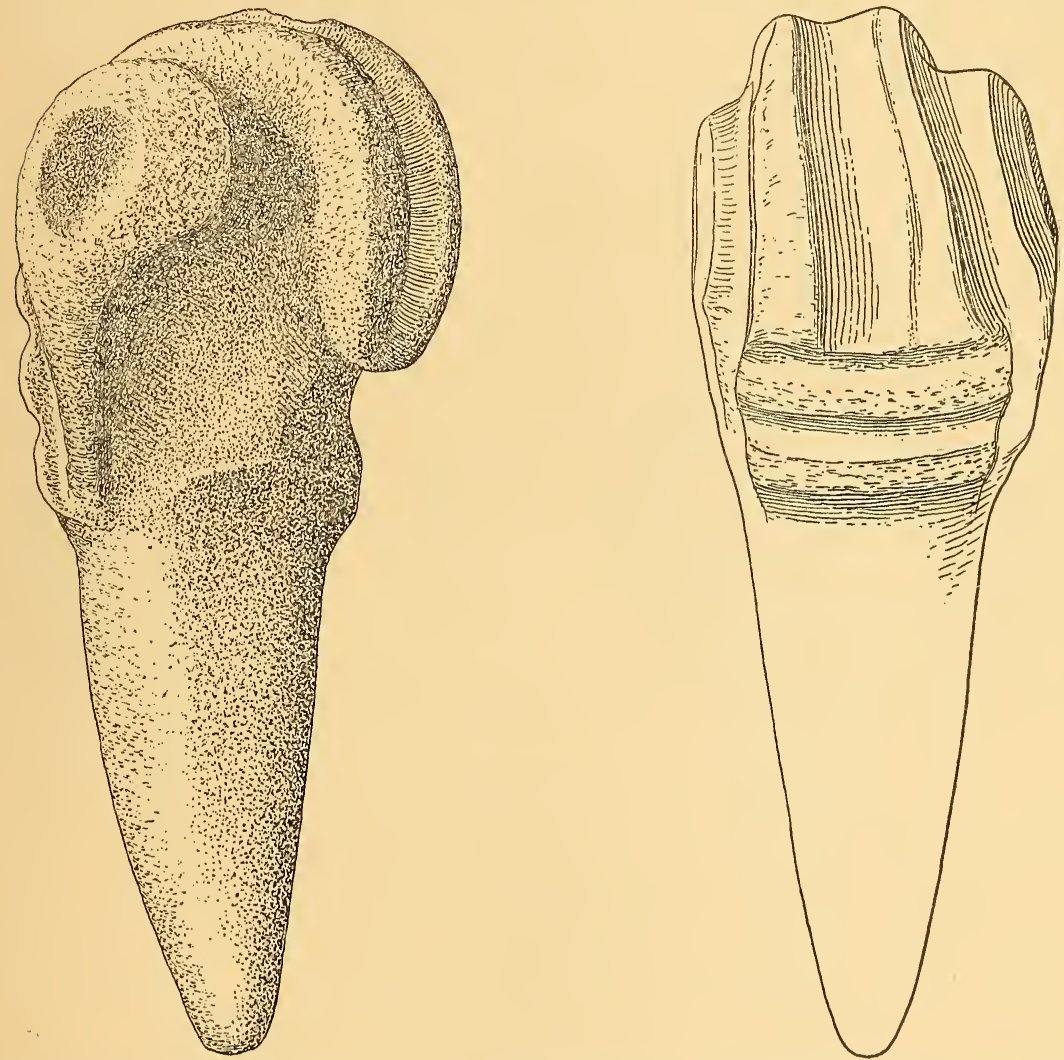

FIG. I28.-Two views of a stone ceremonial baton in the Heye Museum. (Length $6 \frac{4}{5}$ inches.)

ent from that of any yet described, and would suggest that it was carried in the hand, but it may have been inserted into a wooden

1 The "figure trouvée dans une sepúlture indienne," figured by Charlevoix (Histoire de l'Isle Espagnole ou de St. Domingue, p. 6), is believed to be a ceremonial baton similar in function to the object here considered.

2 Many different forms of batons made of stone, wood, and even clay, might be enumerated. A wooden stick with an animal, or rather tivo animals, carved on the end is figured in the author's Aborigines of Porto Rico.

AM. ANTH., N, S., $\mathrm{r}_{5}-3^{\mathrm{r}}$ 
staff. One end of this object is enlarged, with the surface cut into a definite form, while the other end tapers uniformly, providing the handle, possibly for attachment to a rod. The figure on the larger end has a median crest or ridge extending over the extremity, on each side of which is a prominence, the arrangement recalling the crest and eyes of some highly conventionalized animal. The crest or ridge is found on examination to be double and to extend
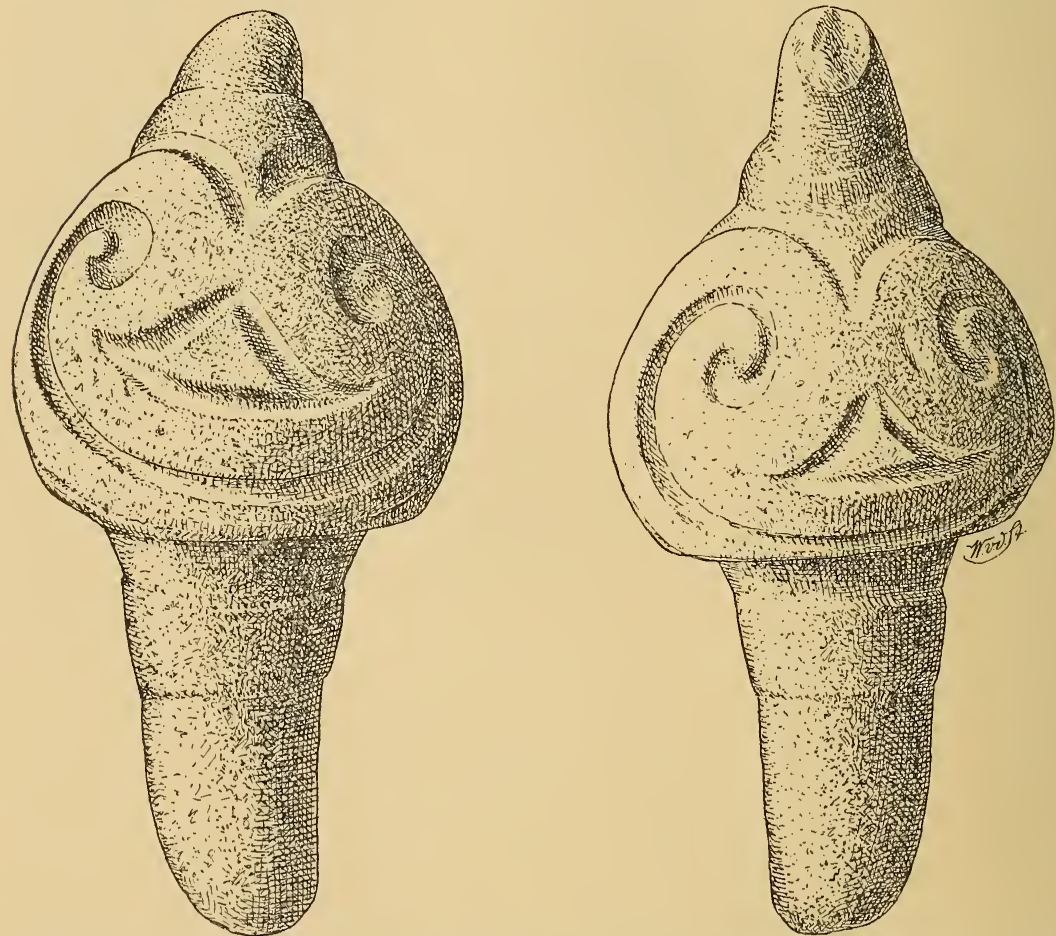

FIG, I29.-Two views of a stone ceremonial baton in the Museum für Völkerkunde; Berlin. ' (About one-third size.)

round the larger end, the two parts coalescing at one end and uniting by a transverse band on the other. On the sides of this median crest are the protuberances, each with a circular pit and extension from the margin. The only object known to the writer that approaches in form the stone referred to is one made of burnt clay found in Barbados, many miles away. This specimen ${ }^{1}$ also has an

1 Now in the Cornell collection at St Kitts, British West Indies. 
enlargement representing a head at one end and tapers uniformly to the other extremity in the form of a handle. The Barbados object also has a crest extending along the middle of the enlarged part and ending abruptly near a hole which may be likened to a mouth; on each side of this elevation there are pits that may be regarded as eyes. The ridge or crest suggests a distorted nose, or the beak of a bird, a suggestion that would seem to comport with the parts on the enlarged end of the stone baton above described. The double median fold and lateral elevations with pits represent beak and eyes.

Another stone object, from an unknown locality, described by Professor Mason, evidently belongs to the same type as the stone ceremonial baton, or some form of badge mounted on a staff. Mason's description of this object is as follows:

Fig. 197. An ornamented stone of a marble gray color. The right part is conoidal and has near its middle a raised band. This may have fitted a socket. The left part resembles a liberty cap, bounded at its base by a curve of beauty. On the two sides of the enlarged middle are compound scrolls in relief, resembling the implements sold to draughtsmen for making curves. Length II $\frac{1}{2}$ inches. The accompanying illustration (fig. I29) is from a drawing of this object in the Guesde collection in the Museum für Völkerkunde in Berlin.

\section{UsE OF ElBow-STONES}

The author believes that stone collars and elbow-stones were used for similar ceremonial purposes. They are regarded as idols (zemis), and the figures sculptured upon them are supposed to represent spirits (zemis). The arms of elbow-stones are interpreted as extensions by which these idols were attached to a foreign body, and are regarded morphologically as rudiments, survivals of more elaborate objects, possibly the same as the shoulders of stone collars. It is believed that the spirit represented by the faces on the elbow-stones is a bark or tree spirit, and that possibly it is the being that caused the manioc, a plant of prime importance to the ancient Antilleans, to germinate and increase. This spirit the Antilleans of Porto Rico and Haiti called Yucayu.

Bureau of American Ethnology

WASHINGTON, D. C. 





